\title{
Appropriate Complementary Feeding Practice and associated factors among mothers with children age 6- 23 months in Faggeta-Lekoma District, Northwest Ethiopia: community- based cross - sectional study
}

\section{Addisu Belete Ferede}

nutrition international awi zone health department

Gashaw Andargie Bikes

University of Gondar College of Medicine and Health Sciences

Tsgehana GebreGyorgis Gebremichael ( $D$ hanagmichael@gmail.com )

Axum university https://orcid.org/0000-0002-6203-5968

Research note

Keywords:

Posted Date: August 14th, 2019

DOI: https://doi.org/10.21203/rs.2.12833/v1

License: (c) (1) This work is licensed under a Creative Commons Attribution 4.0 International License.

Read Full License 


\section{Abstract}

Abstract Objective: the aim of the study was to assess appropriate complementary feeding practices and associated factors among mothers with children of age 6 - 23 months in Faggeta-Lekoma District, Northwest Ethiopia. Result - A total of 593 study subjects were included in the study. The magnitude of appropriate complementary feeding practice was $10.6 \%$. Majority $(67.1 \%)$ of the mothers timely initiated complementary feeding at 6 months. About $60 \%$ of mothers fulfill the minimum meal frequency feeding to their children, the day preceding the survey. Only $12.3 \%$ mothers offered four or more food groups to their child Mother's education: high school and above [AOR=3.12(95\% $\mathrm{Cl} 1.43,6.81)]$, postnatal care visit [AOR=5.30 $(95 \% \mathrm{Cl} 2.69,10.42)]$, Age of a child: $18-23$ months [AOR=3.98 $(95 \% \mathrm{Cl} 1.55,10.22)]$ were significantly associated with appropriate complementary feeding practice. Keywords: appropriate Complementary feeding practice, Children aged 6-23 months, Ethiopia

\section{Introduction}

The first 2 years of life are critical time to promote optimal child growth and development $(1,2)$. After the age of sixth month, the energy and nutrient content of breast milk alone is not enough to meet nutritional requirement of the growing infant $(3,4)$.

The World Health Organization (WHO) recommends that Infants should be exclusively breastfed for the first six months of life. Thereafter, they should receive nutritionally adequate and safe complementary foods at 6 month, while continuing to breastfeed for up to two years or beyond to achieve optimal growth, development and health (5-7).Different studies also supports and proves the current infant feeding recommendations for better growth during infancy and early childhood(8).

Appropriate complementary feeding after the age of 6 month is very essential for prevention of respiratory Infections, diarrhea, stunting, acute malnutrition, micronutrient deficiencies(9). Additionally, appropriate complementary feeding during this period has especial importance to improve cognitive and psychosocial development, productivity and economic status during adult life (10).

Suboptimal (inadequate) infant feeding practices are the major causes for childhood under nutrition in developing countries $(11,12)$. Malnutrition is the cause for $45 \%$ of child death in 2015 globally and one third of the malnourished children were found in Africa (13). Inappropriate feeding practices (inappropriate breast feeding and inappropriate 
complementary feeding) are responsible for $13 \%$ and $6 \%$ of child mortality respectively (9).

The development of successful interventions to improve child-feeding practices, in particular, requires appropriate instruments that can adequately assess current Feeding practices and assessing the factors which have effect on the feeding practice (14).There is little information on appropriate complementary feeding practice( CFP) in Ethiopia. Furthermore, there is no study done on the study area hence this study sought to assess the appropriate complementary feeding practices and its associated factors among children aged 6-23 months who reside in Faggeta-Lekoma District, North Ethiopia.

\section{Main Text}

Community-based cross-sectional study was done from September 9 to September 28, 2017 in Faggeta lekoma district, Amhara region, Ethiopia. The district has 27 kebeles (25 rural and 2 urban kebeles).This study was done among 6 kebeles of the district. The study population was all mothers who have children aged 6-23 months living in the study area for at least 6 months. Mother's who were unable to speak and/or seriously ill at the time of data collection were excluded. Sample size was determined both using single population proportion formula $([\mathrm{n}=[(\mathrm{Za} / 2) * \mathrm{P}(1-\mathrm{P})] / \mathrm{d})$ and by considering the predictor variable (table 1).

Table1: Sample size determination for appropriate CFP and associated factors in Faggeta Lekoma District, Northwest Ethiopia 2018

\begin{tabular}{|c|c|c|}
\hline Variables & Assumption & $\begin{array}{l}\text { Total sample } \\
\text { size }\end{array}$ \\
\hline Appropriate CF practice & $\begin{array}{l}\text { Prevalence }(P)=10.75 \% \text {, marginal error } 4 \% \text {, } \\
\text { CI }=95 \%\end{array}$ & 223 \\
\hline $\begin{array}{ll}\text { iteracy } & \text { rate/Education } \\
\text { level } & \end{array}$ & $\begin{array}{l}\mathrm{OR}=3.84, \mathrm{P}=72.3 \%, \quad \text { power }=80 \%, \mathrm{CI}=95 \% \\
\text { Ratio }=1: 1\end{array}$ & 288 \\
\hline $\begin{array}{l}\text { Age of child (in age } \\
\text { group) }\end{array}$ & 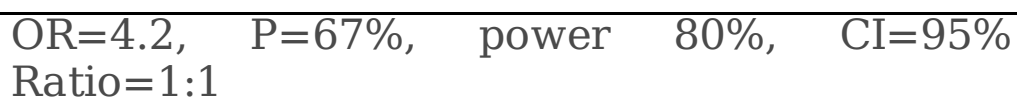 & 202 \\
\hline $\begin{array}{l}\text { Antenatal } \quad \text { care(ANC) } \\
\text { Eollow up }\end{array}$ & $\begin{array}{l}\mathrm{OR}=2.8, \mathrm{P}=66.7 \%, \text { power } 80 \%, \mathrm{CI}=95 \%, \\
\text { Ratio=1:1 }\end{array}$ & 156 \\
\hline
\end{tabular}


The higher sample size which is 288 was taken. By considering design effect of 2 and 5\% for non response a final sample size of 605 was considered. After proportionally allocation of the expected sample size in to the selected 6 kebeles, study subjects were selected by simple random sampling method by using lists from the health post registration book.

Data collection methods and quality assurance procedures

Data were collected using pretested, structured interviewer administered questionnaire. Pretest was done on $5 \%$ of mothers. Two days training was given to data collectors and supervisors.To measure the feeding frequency and dietary diversity 24 hour food intake recall method was used.

\section{Complementary feeding practice indicators}

Timely introduction of complementary feeding: children 6-23 months of age who started complementary foods at 6 month (16).

Minimum dietary diversity: children 6-23 months of age who receive foods from four or more food groups during the previous day. The seven food groups are: grains, roots and tubers; legumes and nuts; dairy products (milk, yogurt, cheese); flesh foods (meat, chicken and liver/organ meats); eggs; vitamin A rich fruits and vegetables; and other fruits and vegetables (16).

Minimum meal frequency: children 6-23 months of age who receive solid, semi-solid or soft foods the minimum number of times or more (minimum is defined as: two times for breastfed infants 6-8 months; three times for breastfed children 9-23 months; and four times for non-breastfed children 6-23 months) in the previous day(16).

Appropriate Complementary Feeding Practices: if the mother responds correctly all the above three indicators (if initiated Timely, fed Minimum dietary diversity and gave Minimum meal frequency) $(17,18)$.

\section{Data management and analysis}

Data were coded and entered into Epi-info version 3.5.1 and exported into statistical package for social sciences (SPSS) Version 21.0 software for analyses. To identify factors associated with appropriate complementary feeding practice, first a bivariable logistic regression was performed. Subsequently, significant variables in the bivariable analysis ( $p$ value $<0.2$ ) were incorporated into the multivariable logistic regression. 


\section{Results}

\section{Socio-demographic characteristics}

Out of 605 mothers, 593 respond to the questionnaire making the response rate 98\%.The mean ( \pm SD) age of mothers and children was 29.13 ( \pm 6.17 ) years and 16.28 ( \pm 5.88) months respectively. Three hundred twenty one (54.1\%) of the respondents were in the age range of 25-34 years followed by those in the age range 35-49 years which accounts for 143 (24.1\%). Majority of the respondents were farmers in occupation which accounts $80.4 \%$ (Table 2).

\section{Maternal and child health services variables}

Three hundred four (51.3\%) of the children were in the age group of 18-23 months. Regarding to the ANC visit, 91(15.3\%) of the mother's didn't attend ANC visit during their pregnancy time. About $40.3 \%$ of mothers give birth their last child at health facility and $37.9 \%$ had received postnatal care at least once (Table 2).

Table 2: Socio-demographic, Maternal and child health services related characteristics of mothers with children 6-23 months of age $(n=593)$ in Faggeta Lekoma District, Northwest Ethiopia 


\begin{tabular}{|c|c|c|}
\hline Variable & Frequency & Percentage \\
\hline $\begin{array}{l}\text { Age of the mother } \\
15-24 \\
25-34 \\
35-49\end{array}$ & $\begin{array}{l}129 \\
321 \\
143\end{array}$ & $\begin{array}{l}21.8 \\
54.1 \\
24.1\end{array}$ \\
\hline $\begin{array}{l}\text { Religion } \\
\text { Orthodox } \\
\text { protestant }\end{array}$ & $\begin{array}{l}591 \\
2\end{array}$ & $\begin{array}{l}99.7 \\
0.3\end{array}$ \\
\hline $\begin{array}{l}\text { Education status of the mother } \\
\text { No formal education } \\
\text { Primary education } \\
\text { Secondary and above }\end{array}$ & $\begin{array}{l}408 \\
113 \\
72\end{array}$ & $\begin{array}{l}68.8 \\
19.1 \\
12.1\end{array}$ \\
\hline $\begin{array}{l}\text { Mother's occupation } \\
\text { Farmer } \\
\text { Housewife } \\
\text { Merchant } \\
\text { Civil servant } \\
\text { Other } \\
\end{array}$ & $\begin{array}{l}477 \\
63 \\
24 \\
17 \\
12\end{array}$ & $\begin{array}{l}80.4 \\
10.6 \\
4 \\
2.9 \\
2.1\end{array}$ \\
\hline $\begin{array}{l}\text { Place of residence } \\
\text { Rural } \\
\text { Urban }\end{array}$ & $\begin{array}{l}493 \\
100 \\
\end{array}$ & $\begin{array}{l}83.1 \\
16.9 \\
\end{array}$ \\
\hline $\begin{array}{c}\text { Fathers' education status } \\
\text { No formal education } \\
\text { Primary education } \\
\text { Secondary and above }\end{array}$ & $\begin{array}{l}287 \\
196 \\
84\end{array}$ & $\begin{array}{l}50.6 \\
34.6 \\
14.8\end{array}$ \\
\hline $\begin{array}{c}\text { Age of the child(months) } \\
6-11 \\
12-17 \\
18-23\end{array}$ & $\begin{array}{l}142 \\
147 \\
304\end{array}$ & $\begin{array}{l}23.9 \\
24.8 \\
51.3\end{array}$ \\
\hline $\begin{array}{l}\text { Sex of the child } \\
\text { Male } \\
\text { Female }\end{array}$ & $\begin{array}{l}305 \\
288\end{array}$ & $\begin{array}{l}51.4 \\
48.6\end{array}$ \\
\hline $\begin{array}{l}\text { ANC visit } \\
\text { Yes } \\
\text { No }\end{array}$ & $\begin{array}{l}502 \\
91\end{array}$ & $\begin{array}{l}84.7 \\
15.3\end{array}$ \\
\hline $\begin{array}{l}\text { Advise about CFP during ANC visit }(\mathrm{n}=502) \\
\text { Yes } \\
\text { No }\end{array}$ & $\begin{array}{l}319 \\
183\end{array}$ & $\begin{array}{l}63.5 \\
36.5\end{array}$ \\
\hline $\begin{array}{l}\text { Place of delivery } \\
\text { Home } \\
\text { Health institution }\end{array}$ & $\begin{array}{l}354 \\
239\end{array}$ & $\begin{array}{l}59.7 \\
40.3\end{array}$ \\
\hline $\begin{array}{c}\text { Postnatal care visit } \\
\text { Yes } \\
\text { No }\end{array}$ & $\begin{array}{l}225 \\
368\end{array}$ & $\begin{array}{l}37.9 \\
62.1\end{array}$ \\
\hline
\end{tabular}


Majority (67.1\%) of the mothers timely initiated complementary feeding at 6 months. About $60 \%$ of mothers fulfill the minimum meal frequency feeding to their children, the day preceding the survey. Only $12.3 \%$ mothers offered four or more food groups to their child meeting the minimum dietary diversity criteria on the day preceding the study. The most commonly given food items to the children in 24 hours preceding the survey were Grain, roots and tubers. From the three combining indicators, overall prevalence of appropriate complementary feeding practices was $10.6 \%$ (95 \% $\mathrm{CI}=8.12,13.07)$.

\section{Factors associated with appropriate complementary feeding practice}

In this study, Age of the child, post natal care visit and mother's education were positively associated with appropriate CFP. Mothers with secondary and above education were 3 times more likely to practice appropriate CFP than mothers with no formal education [AOR $(95 \% \mathrm{CI})=3.12(1.4-6.8)]$.

Mothers who had post natal care visit were 5.3 times more likely to practice appropriate CFP as compared to mothers who had no post natal care visit[AOR $(95 \%$ CI $)=5.3(2.69,10.4)]$. Children in the age group of 18-23 month were3.9 times more likely to receive appropriate complementary foods than children in the age group of 6-11 month [AOR (95\%CI) =3.98 (1.55 -10.2)] (table 3).

Table 3: Factors associated with appropriate complementary feeding practice among mothers who had children aged 6-23 months in Faggeta Lekoma District, Northwest Ethiopia,

$$
* \mathrm{p}<0.05
$$

\section{Discussion}

In this study the magnitude of appropriate CFP was $10.6 \%$. This magnitude is higher than results of studies done in different parts of Ethiopia:7\% in Bahir Dar (19).This might be due to study area difference because the study in Bahirdar is only in urban areas by which the mothers of these children could be employed so it can affect the time of initiation of complementary food which is one of the indicators of appropriate complementary feeding practice.

The magnitude of appropriate complementary feeding practice in this study was lower 
Variables

Appropriate CFP

Yes

N (\%)
No

$\mathrm{N}$
COR

[95\% CI]
AOR

[95\% CI]

(\%)

\section{Mothers'}

education

No formal

education

Primary

education(1-8)

Secondary and above

Husbands'

education

No

education

Primary

education(1-8)

Secondary and

above

Place of

delivery

Home

Health

institution

Postnatal

care visit

No

Yes

Place of

Residence

Rural

Urban

Advice at ANC

about CFP

20(10.2)

22(26.2)

21(7.3)
384(94.1)

1.00

1.00

17(15)

96(85)

2.83[1.46-5.48]

$1.74[0.8,3.7]$

22(30.6)

7.04[3.67-13.5]

$3.12[1.4,6.8]^{*}$

50(69.4)

266(92.7)

1.00

1.00 

6-11
$6(4.2)$
136(95.8)
1.00
1.00

\begin{tabular}{rcrrr}
$12-17$ & $13(8.8)$ & $134(91.2)$ & $2.19[0.81-5.96]$ & $2.39[0.82-6.95]$ \\
\hline $18-23$ & $44(14.5)$ & $260(85.5)$ & $3.83[1.59-9.23]$ & $3.98\{1.55,10.2]^{*}$
\end{tabular}

than results of studies done in different parts of Ethiopia: 56.5\% in Lasta District (20), $29.3 \%$ in oromia (21) and results of studies done in other developing countries, like 47\% in Nigeria (22), 33\% in Nepal (23). This difference could be explained by higher maternal literacy rate and utilization of institutional delivery in the latter study areas, which are the effective entry points to step up mothers' confidence in challenging the community attitude towards inappropriate feeding practices.

The result of multivariable analysis showed that education status of mothers was associated with appropriate complementary feeding practice. Children within the age group 18-23 months were 3.98 times more likely to feed appropriately as compared to infants in the age group 6-11 months. This result was consistent with the results of studies done in Ethiopia (17), Gana (14). This might be due to myth of mothers that infants could not be able to digest food like meat, egg and vegetables before the age of one year than the older children. Furthermore, some of the mothers could not introduce complementary feeding at six months.

Furthermore, the increased odds of appropriate complementary feeding practice were found among mothers who had postnatal care visit than mothers who hadn't the visit. Similar findings were also reported by the studies done in different parts of Ethiopia $(17,19,20)$. This might be due to the fact that during post natal care visit mothers are more likely to get advice and Education on appropriate infant and young child feeding practice hence it can contribute to improved feeding practice of the children.

This study also showed that education status of the mother is important predictor to appropriate complementary feeding practice. Mothers with secondary and above education were 3.12 times more likely to practice appropriate complementary feeding practice than mothers with no formal education. Similar finding were also reported by studies done in different parts of Ethiopia $(17,18,19)$. The possible reason for this might be educated 
mothers can easily access information from different source and could have better understand about Importance of appropriate CFP.

\section{Conclusions}

Appropriate Complementary feeding practice was low in Faggeta-Lekoma District. Mothers' education status, Age of the child and mothers postnatal check up were significantly associated with appropriate complementary feeding practice. Increasing the coverage of postnatal care utilization and mothers' education is crucial to practice appropriate complementary feeding practices.

\section{Limitations}

Recall and social desirability bias may be introduced because frequency, types of foods and time of initial depends on respondent's memory.

\section{Abbreviations}

AOR: Adjusted odds ratio; WHO: World Health Organization; CFP: complementary feeding practice; ANC: Antenatal care; SD: Standard deviation; CI: confidence interval; SPSS: Statistical package for social sciences; COR: Crude odds ratio

\section{Declarations}

\section{Ethics approval and consent to participate}

Ethical clearance was obtained from institutional ethical review board, institute of public health, University of Gondar. Permission letters was obtained from Faggeta Lekoma District Health Office. All participants were informed about the purpose of the study there after written consent was obtained. Confidentiality was maintained by using code numbers other than names.

\section{Consent for publication}

Not applicable

\section{Availability of data and materials}

Data will be available upon request from the correspondence authors 


\section{Competing interests}

The authors declare that they have no competing interests

\section{Funding}

This study was self sponsored. The principal investigator covers the cost for the study.

\section{Authors' contributions}

Conceived and designed the study: AB, TG, GA. Performed the study: AB. Analyzed the data: AB, TG, GA, Wrote the paper: AB, TG, Approved the proposal with some revisions: AB, TG. All authors read and approved the final manuscript

\section{Acknowledgements}

The authors would like to express their sincere gratitude to those mothers for their willingness and positive cooperation for being part of our study. The authors' heartfelt thanks will also goes to Faggeta-Lekoma District for the provision of available data about the district.

\section{References}

1. World Bank. Repositioning nutrition as central to development: a strategy for large-scale action-overview .Directions in development. Washington, DC: 2006

2. Victora CG. deOnis M, Hallal PC, Blo“ssner M, Shrimpton R. Worldwide timing of growth faltering: Revisiting implications for interventions using the World Health Organization growth standards. Pediatrics. 2010; 125: 473-80

3. WHO. Guiding principles for complementary feeding of the breastfed child;2001

4. Ruel M, Hoddinott J, Investing in Early Childhood Nutrition. Policy Brief. 2008;8:4

5. World Health Organization. Infant and young child feeding: model chapter for textbooks For medical students and allied health professionals. Infant and young child feeding: model chapter for textbooks for medical students and allied health professionals. 2009 6. World Health Organization, UNICEF. Global strategy for infant and young child feeding: World Health Organization; 2003

7. World Health Organization. Guiding principles for feeding non-breastfed children 6-24 months of age. 2005 
8. Kuntal K, Edward A, Dewan S, Shams E, Lars A,et.al.Appropriate infant feeding practices result in better growth of infants and young children in rural Bangladesh: American journal of clinical nutrition.2008;87:1852-9

9. UNICEF. Progrmming guide for infant and young child feeding. New York: UNICEF; 2011

10. Chessa K, Bernadette M, Mercedes de Onis, Monica T, Marie T, Mary A, et al. Undernutrition, Poor Feeding Practices, and Low Coverage of Key Nutrition Interventions. Pediatrics. 2011;128

11. Edem MAT, Eric KS, Tete-DonkorPriscilla, Peter N-A, Edmund TN. Feeding practices and malnutrition at the Princess Marie Louise Children's hospital,Accra: what has changed after 80 years? BMC Nutrition.2016;2:42

12. Rah J, Akhter N, Semba R, Sd P, Bloem M, Campbell A, et al. Low dietary is a predictor of child stunting in rural Bangladesh. Eur J Clin Nutr.2010;64:1393-8

13. UNICEF. Levels and trends in child malnutrition UNICEF-WHO-World Bank Group Joint child malnutrition estimates.2015

14. Mahama S,Asamoah L,Sofo M and Irmgard H. Magnitude and factors associated with Appropriate complementary feeding among children 6-23 months in Northern Ghana: BMC Nutrition.2016

15. Mekbib E, Shumey A, Ferede S, Haile F. Magnitude and factors associated with appropriate complementary feeding among mothers having children 6-23 months-of-age in Northern Ethiopia; a community-based cross-sectional study. Journal of Food and Nutrition Sciences $2014 ; 2(2): 36-42$

16. WHO, UNICEF, USAID, FANTA, AED, UC DAVIS, and IFPRI. Indicators for assessing infant and young child feeding practices part 2: measurement. Geneva: The World Health Organization; 2010

17. Ergib M, Ashenafi S, Semaw F, Fisaha H. Magnitude and factors associated with appropriate

Complementary feeding among mothers having children 6-23 months-of-age in Northern Ethiopia; a community-based cross-sectional study: Journal of Food and Nutrition Sciences. $2014 ; 2(2): 36-42$ 
18. Tigist K, Berhan M, Yusuf H, Jemal E. Appropriate complementary feeding practices and associated factors among mothers of children age 6-23 months in Southern Ethiopia: BMC Pediatrics.2016; 16:131

19. Yeshalem M, Tadese E, Dereje B. Infant and young child feeding practice among mothers with 0-24 months old children in Slum areas of Bahir Dar City, Ethiopia: International Breastfeeding Journal.2017;12:26

20. Menberu M, Tadese E, Girma N. Complementary Feeding Practice and Associated Factors among Mothers Having Children 6-23 Months of Age, Lasta District, Amhara Region, Northeast Ethiopia: Advances in Public Health. 2017

21. Wondu G, Nianhong Y. Determinants of Suboptimal Complementary Feeding Practices among Children Aged 6-23 Months in Selected Urban Slums of Oromia Zones: Journal of Nutrition \& Food Sciences. 2017;7:3

22.Foluke A, Jesupelumi O, Sunday A, Oluwafunmilayo F. Complementary Feeding Knowledge, Practices, and Dietary Diversity among Mothers of Under-Five Children in an Urban Community in Lagos State, Nigeria: International Journal of $\mathrm{MCH}$ and AIDS.2017;6(1):46-59

23. Kapil P, Mandira A, Resham B, Madhu D. Determinants of infant and young child feeding practices in Rupandehi, Nepal: BMC research note.2016;9: 135 